\title{
Desiliconized Pig Iron For the Electric
}

\section{Furnace-A Possibility}

\author{
Hot-charging of pig iron into the electric furnace is a \\ subject of much interest. The advantages of desiliconizing \\ the pig before charging, as here presented, make an important \\ difference in costs.
}

\author{
by S. L. Case
}

\begin{abstract}
$A^{\prime}$ $\mathrm{N}$ investigation of the comparative economics of open-hearth and electric furnaces for production of low-carbon steel, published in $1953,{ }^{1}$ showed that, in an integrated steel plant, the economics of the electric furnace as a steelmaking unit compared favorably with those of an open hearth. It was pointed out, however, that the problem of operating an electric furnace on a charge containing a high percentage of hot metal hasn't been solved as yet. One of the important stumbling blocks in such an operation is the high silicon content of the charge, when the ratio of hot metal to scrap is 1 to 1 , or higher.
\end{abstract}

Each pound of silicon added to the furnace charge produces over $2 \mathrm{lb}$ of silica, which in turn requires about $6 \mathrm{lb}$ of lime to produce a slag of desirable characteristics. If the $\mathrm{SiO}_{2}$ content of the furnace slag at the final stage of refining averages about 15 pct, the slag volume resulting from each 0.1 pct of $\mathrm{Si}$ in the 50-ton hot-metal charge will approximate $1500 \mathrm{lb}$. It is, thus, evident that, if the hot metal were desiliconized as a preliminary step to charging into the furnace, the amount of slag carried by the bath would be greatly reduced. As an example, if the desiliconization could reduce the silicon content of the hot metal by 0.7 pct, slag volume in a 100 -ton heat would be reduced by about 10,500 lb. Also, $4200 \mathrm{lb}$ of burned lime could be saved on each heat, and ingot yield would be substantially increased, because the slag carries from 12 to 20 pct $\mathrm{FeO}$, depending on the grade of steel being made. Reduced volume of slag will also result in decreased consumption of electrical energy.

A very informative paper on the economics of desiliconization in electric-furnace steelmaking was published by E. C. Wright in January, $1956 .^{2}$ Wright bases his calculations of material and heat balances on the premise that standard hot metal contains 4.0 pet $\mathrm{C}$ and 1.0 pct $\mathrm{Si}$, and that desiliconized or washed hot metal contains 2.0 pct $\mathrm{C}$ and 0.1 pct Si. Insofar as electrical energy requirements are concerned, Wright's calculations show that on a 50:50 hot-metal charge, use of desiliconized iron will reduce electrical energy requirements by about 63 pct $-456 \mathrm{kwhr}$ per ton of liquid steel for standard hotmetal charge vs. $289 \mathrm{kwhr}$ for a washed hot-metal

S. L. CASE is with the Battelle Memorial Institute, Columbus, Ohio. This paper to be presented at the Electric Furnace Steel Conference, Chicago, December, 1956. charge. With nearly all of the silicon and about half of the carbon in the metal being removed by the desiliconization treatment, it should be possible to operate the electric furnace on a higher ratio of hot metal to scrap in the charge. Under such a practice, the saving in electrical energy requirements should be even greater than for the 50:50 practice. For $60: 40$ and 70:30 ratios of hot metal to scrap, Wright's calculated energy requirements are 248 and 220 $\mathrm{kwhr}$ per ton of liquid steel, respectively, assuming a 70 pct efficiency.

Regardless of what process is employed, desiliconization of hot metal for electric furnaces will probably be considered a must in the near future, when operation of electric furnaces on a high hot-metal charge may be expected to become common practice in integrated steel plants. Costs of desiliconization are estimated to range from $\$ 1$ to $\$ 2$ per ton of hot metal. This would be compensated many fold by savings in lime, electrical energy, electrodes, and increased furnace output. Wright ${ }^{2}$ estimates that on a charge of 60 pct washed hot metal and 40 pct scrap, melting rate in a 100-ton electric furnace would approximate $40 \mathrm{tph}$, while on a conventional charge, the hourly output of a similar furnace would, under optimum conditions, average only 24 tons.

The figures cited above give a favorable outlook for desiliconization treatments of hot metal in electric-furnace steelmaking. It should, however, be borne in mind that, up to the present time, there are no reported data on the use of as much as 70 pct hot metal in the electric-furnace charge. Therefore, the desiliconization effects discussed are predictions and extrapolations. There may be some operating complications when electric furnaces are operated on a hot metal charge containing only 0.1 pet silicon, but such complications are not obvious at the present time. What is now known about the so-called duplex open-hearth practice, indicates that the extremely low slag volume of the duplex process does not lead to any dephosporization difficulties, except in rare instances of ladle rephosphorization on highcarbon, thoroughly deoxidized steel, but such difficulties can be readily prevented by a high V-ratio in the slag.

\section{References}

${ }^{1}$ S. L. Case, D. D. Moore, C. E. Sims, and R. J. Lund: Comparative Economics of Open-Hearth and Electric Furnaces for Production of Low-Carbon Steel, Battelle Memorial Institute, Published by Bituminous Coal Research, Inc., July, 1953.

From Desiliconized Hot Metal, Iron and Steel Engineer, January, 1956, pp. 73-85. 